\title{
Noninvasive Estimation of PCWP with Doppler Transmitral Flow Velocity Pattern in Patients with Coronary Artery Disease
}

\author{
RJ Tamanna ${ }^{1}$, R Jahan², AK Akanda ${ }^{3}$, AQM Reza ${ }^{3}$, A Zaher ${ }^{3}$ \\ ${ }^{1}$ Department of Cardiology, Uttara Adhunik Medical College Hospital, BMSRI, Dhaka ${ }^{2}$ Department of \\ Statistics, Jahangir Nagar University, Dhaka ${ }^{3}$ Department of Cardiology, NICVD
}

Key words:
Pulmonary
capillary wedge
pressure,
Doppler
echocardiography,
Coronary
artery disease,
Cardiac
catheterization.

\section{Abstract:}

Background: Pulmonary capillary wedge pressure is an important clinical marker of cardiac function. Recent studies have demonstrated Doppler transmitral flow velocity pattern could be useful in assessing PCWP no invasively in patient with known heart disease.

Objective: The aims of the study were to correlate the Pulmonary Capillary Wedge Pressure (PCWP) estimated by Doppler echocardiography with that obtained at cardiac catheterization and to evaluate the feasibility and accuracy of Doppler echocardiographic data.

Method: All patients underwent simultaneous cardiac catheterization and were studied by Doppler echocardiography. Mitral flow velocity variables \& maximal left atrial volume (MLAV) were correlated with invasive PCWP by both single \& multilinear regression analysis.

Result: A statistically significant negative correlation of deceleration time $(r=-0.483 ; p=0.001)$ and ejection fraction $(r=-0.334 ; p=0.01)$ and a statistically significant positive correlation of peak $E$ wave $(r=0.345 ; p=0.01)$ and deceleration rate $(r=0.651 ; p=0.001$ were found with catheter derived PCWP. Multiple regression analysis was used to derive an equation for noninvasive estimation of PCWP. Equation. With 2-D Echo + Mitral flow variables:

$\mathrm{PCWP}=1.43 \mathrm{X} \mathrm{DR}+1.32 \mathrm{X} \mathrm{E} / \mathrm{A}-0.024 \mathrm{X} \mathrm{DT}+.02 \mathrm{X} \mathrm{MLAV} \mathrm{+} \mathrm{9.2.}$

Conclusion: The correlation coefficient between measured and estimated PCWP from the equation was ( $r=0.678)$. Data indicated that in patients with CAD the noninvasive assessment of transmitral flow velocity pattern by Doppler echocardiography could predict PCWP with a clinically meaningful degree of accuracy.

(Cardiovasc. j. 2009; 1(2) : 174-182)

\section{Introduction:}

Pulmonary capillary wedge pressure is an important clinical marker of cardiac function. Unfortunately clinical and radiological sign does not reliably reflect PCWP. Direct haemodynamic evaluation is therefore required to obtain appropriate information on PCWP and it remains an invasive procedure that result in serious complication. Recent studies have demonstrated Doppler transmitral flow velocity pattern could be useful in assessing PCWP no invasively in patient with known heart disease. ${ }^{1}$ Earlier studies have shown that Doppler indices based on transmitral and pulmonary venous flow provide an accurate means of estimating PCWP ${ }^{2-5}$ better with peak early diastolic filling velocity/flow propagation velocity (E/FPV) by color M-mode Doppler than with other Doppler indices ${ }^{6,7}$. Color M-mode
Doppler LV inflow propagation velocity (LVIPVcmm) has been proven to be related to the time constant of isovolumic LV relaxation (tau). ${ }^{8,9}$ Recently, it has been established that pulsed wave Doppler LV inflow propagation velocity (LVIPVpw) to be related to tau ( $\left.\mathrm{r} \_0.533, \mathrm{P}_{-} .001\right) .{ }^{10}$

Various pulsed Doppler patterns of left ventricular (LV) filling have been described in health and different disease states, ${ }^{11,12}$ but their relationships with the fundamental parameters of diastolic function are very complex and ambiguous ${ }^{1,13}$. Recently color M-mode Doppler echocardiography has been proposed as a useful method for the evaluation of $L V$ relaxation and derived indexes like flow propagation velocity (FPV) have shown a good correlation with the time constant of isovolumic relaxation ( $t$, tau). ${ }^{14-19}$ Taking advantage of this property, color M-mode Doppler indexes has been used for solving the problem of

Address of Correspondance: Dr. Rownak Jahan, Assistant Professor of Cardiology, Uttara Adhunik Medical College Hospital, BMSRI, Dhaka 
differentiating normal from pseudo-normal pulsed Doppler patterns. ${ }^{18}$ In our present study, we aimed at obtaining a noninvasive estimate of PCWP from mitral inflow velocity variables and the study was also designed to test its ability to produce reliable estimate of PCWP in comparison to that obtained at cardiac catheterization

\section{Material and methods:}

We prospectively studied 50 consecutive patients with coronary artery disease admitted the Department of Cardiology, National Institute of Cardiovascular Diseases, Dhaka and underwent catheterization for coronary artery disease between January 2002 to December 2002. All patients were examined and satisfactory Doppler recordings were made in 50 patients. Exclusion criteria included inadequate Doppler recording, mitral stenosis, severe mitral regurgitation and AV block. There were 45 male and 5 female of mean age 47+-8.9. All were in patient undergoing coronary angiogram via right femoral artery. None had clinical evidence of aortic and mitral valve disease and all were in sinus rhythm. 15 (30\%) patient had old MI, 31 (62\%) AMI, 4(8\%) unstable angina. Doppler echocardiographic and Hemodynamic studies were performed sequentially and analyzed in blinded manner by two independent observers.

\section{$M$-mode and $2 D$ - echocardiography}

Two-dimensional and M- mode echocardiography was performed in all patients in the standard manner using commercially available equipments with a $2.5 \mathrm{MHz}$ transducer. This examination was done to assess chamber enlargement and ventricular systolic function. Careful attention was paid to valvular and congenital pathology. Maximal left atrial volume was determined by area length method from $2 \mathrm{D}$ apical 2 and 4 chamber views. Left atrial volume was measured from apical 4 and 2 chamber view of $2 \mathrm{D}$ echo with the aid of following equation.

$\mathrm{MLAV}=\mathrm{V}=8 \div \mathrm{A} 1 \times \mathrm{A} 2 \times 3 \pi \mathrm{L}$ in which

$\mathrm{A} 1=$ area of 4 chamber view

$\mathrm{A} 2=$ area of 2 chamber view $\mathrm{L}=$ common length in the two views (fig-1)

\section{Doppler-echocardiography}

Pulsed Doppler measurement of mitral flow was carried out within $24 \mathrm{hrs}$ of cardiac catheterization. Each valve was evaluated by pulsed wave and continuous wave Doppler echocardiography followed by color mapping. Same technique was also applied to determine congenital shunt abnormality. 2D guided apical 4-chamber view was used to assess transmitral flow parameters. Measurements were made from an average 3 to 5 consecutive velocity curve detected by pulsed wave Doppler. Pulsed Doppler sample volume was placed at the tips of mitral valve leaflets in diastole to see the transmitral flow parameters (fig-2). The following variables were measured during three consecutive cardiac cycles and mean values of three measurements were used for analysis.

Variables: Peak E velocity (early filling), peak A velocity (atrial systole), E/A ratio, deceleration time of early filling (fig-3), deceleration rate, duration of late diastolic velocity wave $\mathrm{dA}$.

Normal \& absolute values of

Mitral inflow velocity variables(Figure 3)

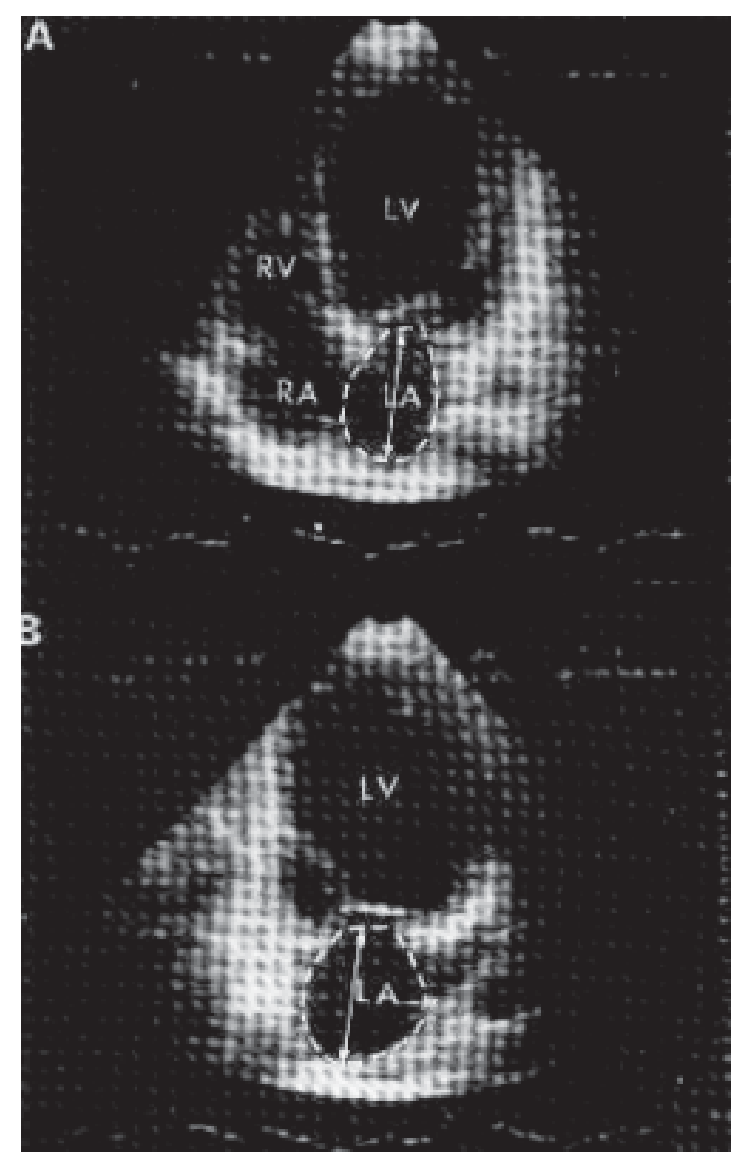

Fig 1.2D Echocardiography, apical four chamber view (Fig-A) and apical 2 chamber view (Fig-B). Measurement of area and length of left atrium. 


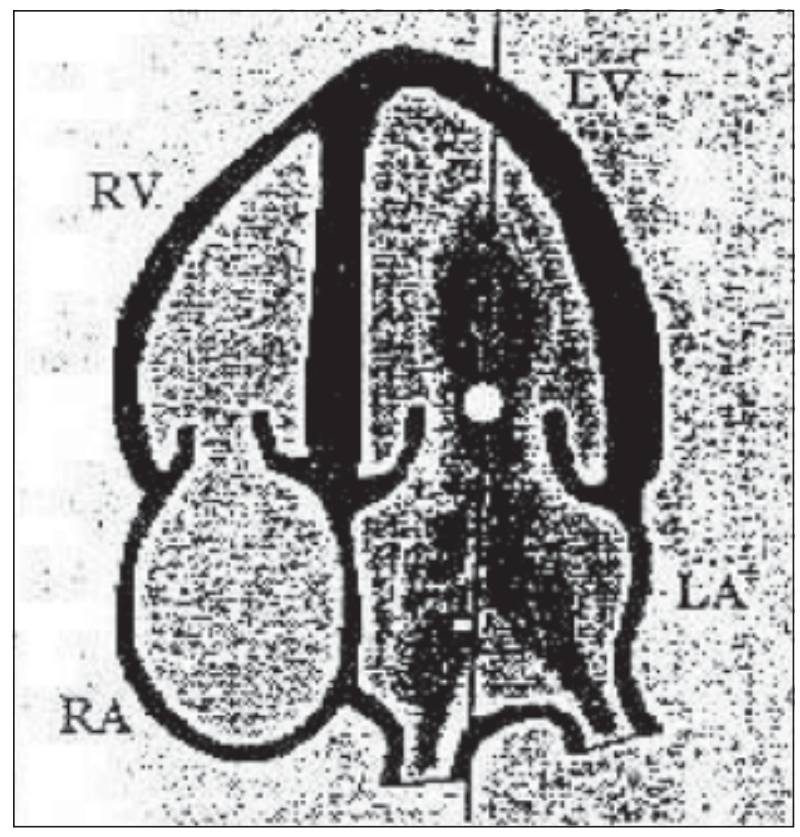

Fig 2. $L V$ diastolic filling. $P W$ Doppler sample volume position

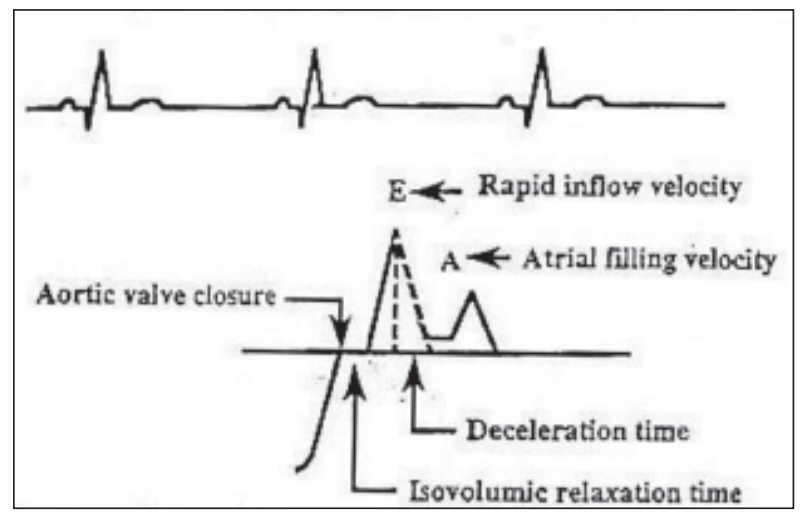

Fig 3. Index of diastolic filling - Mitral inflow

Peak E wave - 53-105- $\mathrm{cm} / \mathrm{s}$

Peak A wave - 26-70- $\mathrm{cm} / \mathrm{s}$

E/A ratio $>1$

E deceleration time DT- $160-220 \mathrm{~m} \mathrm{sec}$

E deceleration rate $\mathrm{DR}=\mathrm{E} / \mathrm{DT}-5.6 \pm 2.7 \mathrm{~m} / \mathrm{sec}^{2}$

Doppler and 2D data obtained were used to generate an equation for estimation of PCWP that was correlated with actual PCWP obtained by cardiac catheterization.

The equation is

$P C W P=1.43 X D R+1.32 X E / A-0.024 X D T+$ $.02 X M L A V+9.2$.

\section{Cardiac catheterization}

Both right sided and left heart catheterization were done in all patients. Modified Seldinger method using right or left femoral vein was applied for right-sided catheterization. PCWP was measured by $6 \mathrm{~F}$ Cournand catheter using transducer at the level of mid-axillary line with patient in horizontal decubitus. Catheter was advanced under fluoroscopic control to inferior vena cava, next to right atrium, right ventricle and pulmonary artery. Next the catheter was advanced to the wedge position. This was done simply by having the patient take a deep breath and holding it while the catheter was advanced until its tip went no further and did not pulsate with the heart. Having the patients cough at this time catheter tip was advanced into a true 'wedge' position. The pressure waveforms (Fig-4) were monitored and if had the appearance of a true wedge, pressure was noted. Blood was sampled from the catheter. The pressure was confirmed as a true wedge pressure only if blood that was completely ( $95 \%$ or more) saturated with oxygen was aspirated gently from the catheter ${ }^{21}$.

Left heart catheterization with CAG and LV graphy were done through femoral arterial approach after right heart catheterization by the femoral protocol for catheterization, carried out in the catheterization laboratory of National Institute of Cardiovascular Diseases.

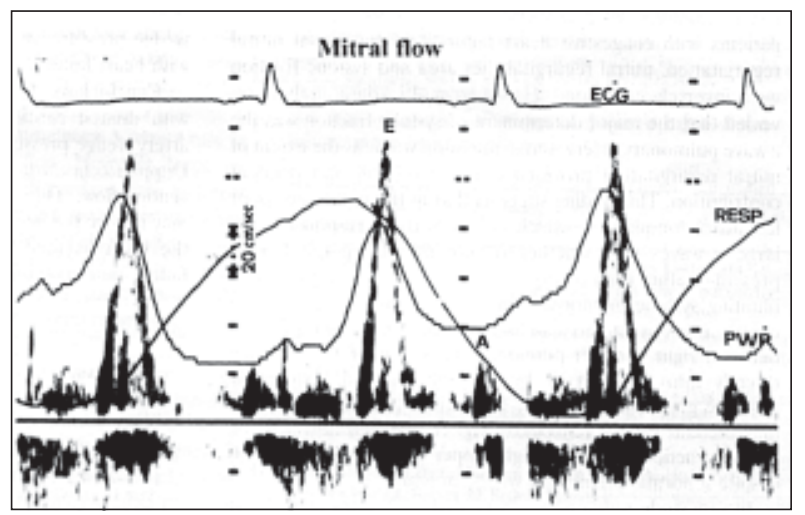

Fig 4. Mitral flow velocity wave simultaneously recorded with pulmonary capillary wedge pressure.

Standard views were taken for both right and left coronary system. Left ventricular end diastolic pressure (LVEDP) was recorded with the aid of $6 \mathrm{~F}$, pigtail catheter before injecting dye into $\mathrm{LV}$ (i.e.LVgraphy) The total population was divided according to catheter derived PCWP, ${ }^{20}$ group I having PCWP $\geq 12-<18 \mathrm{mmHg}$ and group II having $\mathrm{PCWP} \geq 18 \mathrm{mmHg}$ 


\section{Statistical analysis:}

The numerical data obtained from the study were analyzed and significance of differences were estimated by using statistical methods. Computer based SPSS (Statistical Package for Social Science) program was used for all the analysis. Data were expressed in terms of frequencies, percentages and means and standard deviations as applicable. Comparison between two groups according to PCWP was done by student's ' $t$ ' test, chi-square test and Fisher's exact test as applicable. To measure the relationship between catheterderived PCWP and echocardiographic variables Pearson correlation coefficient was used. Stepwise multiple linear regression analysis involving different echocardiographic variables was performed to obtain an estimated PCWP. Then graphical representations, correlation tests and Pearson correlation coefficients were employed to establish the relationship between catheter derived PCWP and estimated PCWP and also to identify the best predictor of measured PCWP. $p$ value of less than 0.05 was considered as significant.

\section{Results:}

In the study we examined 45 men (90\%) and 5 women, with a mean age of $47.0 \pm 8.9$ years (mean $\pm \mathrm{SD}$ ), range 25 to 67 years. Deceleration rate was significantly higher and deceleration time was significantly lower among the patients having $\mathrm{PCWP} \geq 18 \mathrm{mmHg}$ (Tab 1).

A statistically significant negative correlation of deceleration time $(r=-0.483)$ and ejection fraction $(\mathrm{r}=-0.334)$ and a statistically significant positive correlation of peak $\mathrm{E}$ wave $(\mathrm{r}=0.345$ and deceleration rate $(r=0.651)$ were seen with catheter derived PCWP $(\mathrm{p}<0.05)$. (Fig 5\&6). But no significant correlation was found between catheter derived PCWP and peak A wave, E/A ratio, duration of the late diastolic velocity wave (dA), and MLAV ( $p>0.05)$ (Tab 2).

\section{Table-I}

Mean distribution of Doppler Echocardiographic findings of mitral flow in relation to PCWP

\begin{tabular}{|c|c|c|c|c|}
\hline \multirow{2}{*}{$\begin{array}{l}\text { Doppler echocardiography } \\
\text { (Mitral flow) }\end{array}$} & \multirow{2}{*}{$\begin{array}{c}\text { Total }(\mathrm{N}=50) \\
\text { Mean } \pm \mathrm{SD}\end{array}$} & \multicolumn{2}{|c|}{ PCWP } & \multirow[t]{2}{*}{$\mathrm{p}$ value } \\
\hline & & $\begin{array}{c}\geq 12-<18 \mathrm{mmHg} \\
(\mathrm{n}=14) \\
\text { Mean } \pm \mathrm{SD}\end{array}$ & $\begin{array}{c}18 \mathrm{mmHg} \\
(\mathrm{n}=36) \\
\text { Mean } \pm \mathrm{SD}\end{array}$ & \\
\hline$\overline{\text { Peak-E wave (m/sec) }}$ & $0.8 \pm 0.2$ & $0.7 \pm 0.2$ & $0.85 \pm 0.2$ & $0.077^{\mathrm{NS}}$ \\
\hline Peak-A wave $(\mathrm{m} / \mathrm{sec})$ & $0.7 \pm 0.2$ & $0.65 \pm 0.2$ & $0.73 \pm 0.1$ & $0.144^{\mathrm{NS}}$ \\
\hline E/A ratio & $1.2 \pm 0.4$ & $1.18 \pm 0.45$ & $1.20 \pm 0.4$ & $0.895^{\mathrm{NS}}$ \\
\hline Deceleration time (DT) in sec & $0.2 \pm 0.003$ & $0.18 \pm 0.004$ & $0.16 \pm 0.003$ & $0.040^{\mathrm{S}}$ \\
\hline Deceleration rate (DR-E/DT) m/ $/ \mathrm{sec}^{2}$ & $5.1 \pm 1.7$ & $4.26 \pm 0.16$ & $5.3 \pm 1.7$ & $0.040^{\mathrm{S}}$ \\
\hline $\begin{array}{l}\text { Duration of late diastolic velocity } \\
\text { wave (dA) in sec }\end{array}$ & $0.2 \pm 0.03$ & $0.19 \pm 0.04$ & $0.19 \pm 0.03$ & $0.812^{\mathrm{NS}}$ \\
\hline
\end{tabular}

$\mathrm{p}$ value reached from unpaired student's t test

$\mathrm{NS}=$ Not significant $(\mathrm{p}>0.05)$

$\mathrm{S}=$ Significant $(\mathrm{p}<0.05)$

Table-II

Pearson Correlation between different echocardiographic variables and catheter derived PCWP

\begin{tabular}{lcc}
\hline Echocardiographic variables vs & $\begin{array}{c}\text { Pearson Correlation } \\
\text { Catheter derived PCWP }\end{array}$ & p value \\
\hline Peak-E wave (m/sec) & 0.345 & $0.014^{\mathrm{S}}$ \\
Peak-A wave (m/sec) & 0.224 & $0.117^{\mathrm{NS}}$ \\
E/A ratio & 0.066 & $0.648^{\mathrm{NS}}$ \\
Deceleration time (DT) in sec & -0.483 & $0.001^{\mathrm{S}}$ \\
Deceleration rate (DR-E/DT) m/sec & $0.001^{\mathrm{S}}$ \\
Duration of late diastolic velocity wave (dA) sec & 0.651 & $0.200^{\mathrm{NS}}$ \\
MLAV m ${ }^{3}$ & -0.184 & $0.058^{\mathrm{NS}}$ \\
Ejection fraction(\%) & 0.270 & $0.018^{\mathrm{S}}$ \\
\hline
\end{tabular}

$\mathrm{P}$ value reached from correlation test

$\mathrm{S}=$ Significant $(\mathrm{p}<0.05)$ NS $=$ Not significant $(\mathrm{p}>0.05)$ 


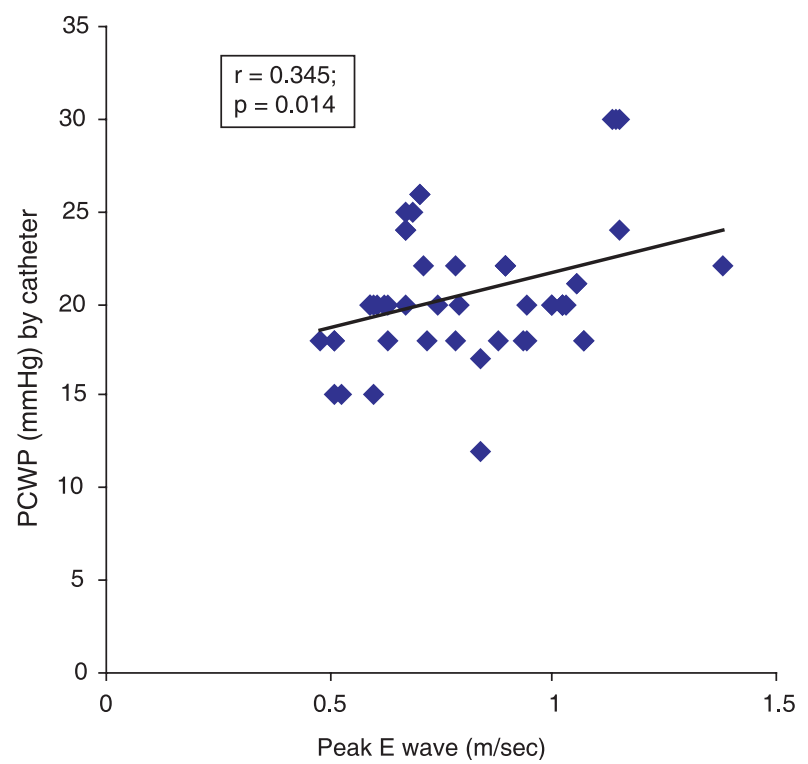

(a)

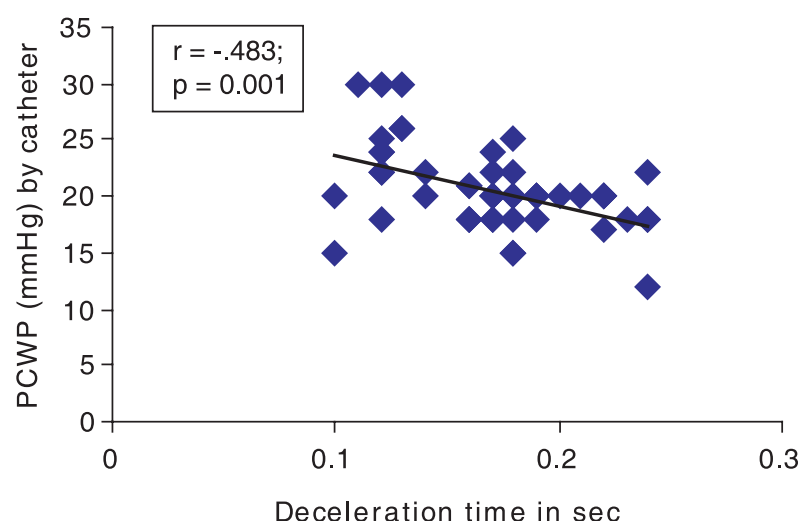

(b)

Fig.-5: Scatterplots showing the correlation between catheter derived PCWP and a) Peak E wave( $\mathrm{m} / \mathrm{sec})$ and b) deceleration time in sec
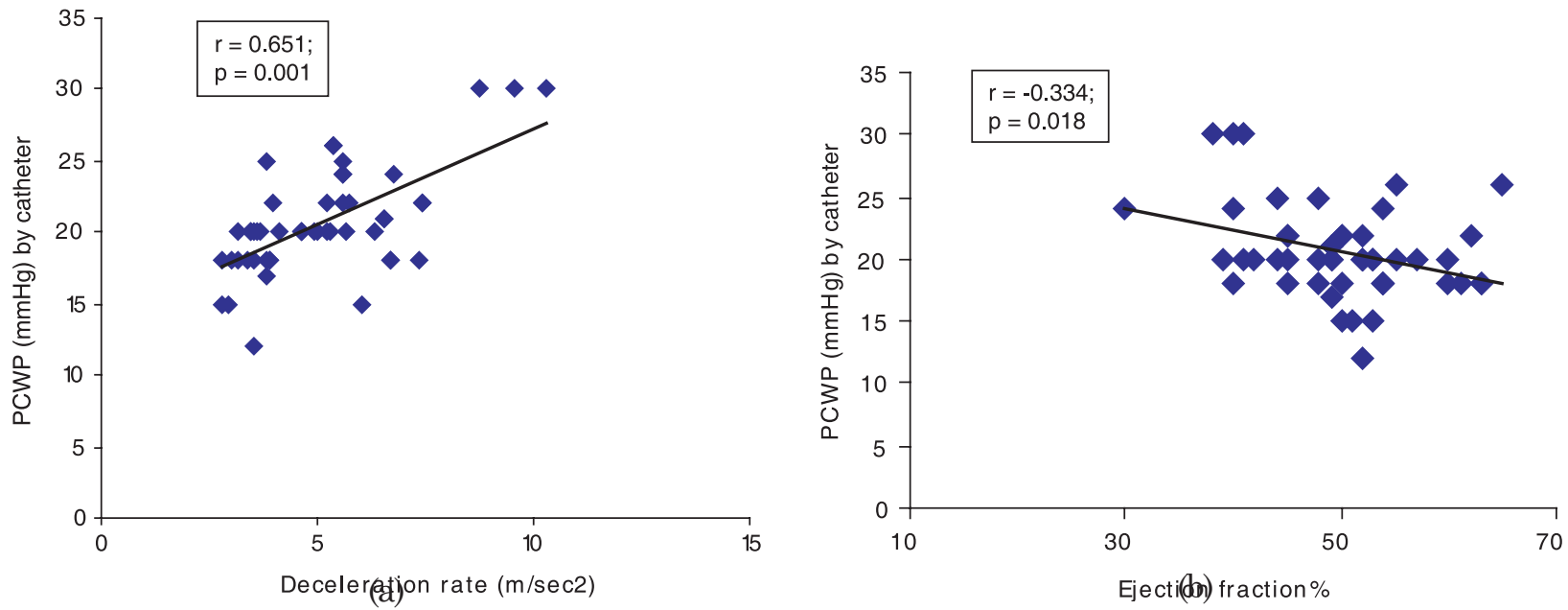

Fig.-6: Scatterplots showing the correlation between catheter derived PCWP and a) Deceleration rate $\left(\mathrm{m} / \mathrm{sec}^{2}\right)$ and $\left.\mathrm{b}\right)$ ejection fraction

When the measurements were combined in stepwise multiple regression analysis there was an incremental gain in the correlation between Doppler measurements and PCWP which was illustrated in (Tab 3) The most important determinant of PCWP was deceleration rate whereas peak early to late diastolic velocity ratio, deceleration time and maximal left atrial volume provided a smaller contribution By combining mitral flow velocity and 2D echocardiographic variables in stepwise multiple linear regression analysis an equation for predicting PCWP was derived. The correlation coefficient between measured and estimated PCWP from following equation

$P C W P=1.43 \times D R+1.32 x E / A$ $0.024 x D T+0.02 x M L A V+9.2$, was $\mathrm{r}=0.678$. 


\section{Table-III}

Stepwise multiple linear regression analysis: Correlation between Pulmonary Capillary Wedge Pressure measured and estimated

Stepwise multiple linear Pearson correlation regression analysis coefficients (r value)

With 2DE and mitral flow variables in study subjects

Deceleration rate

Deceleration rate + Peak early/late diastolic velocity ratio

Deceleration rate + Peak early/late diastolic velocity ratio+ Deceleration time

0.666

Deceleration rate + Peak early/late diastolic velocity

0.678

ratio+ Deceleration time+ maximal left atrial volume

Equation 1 PCWP: 1.43XDR+1.32XE/A- 0.024XDT+0.02XMLAV+9.2

Table-IV

Pearson Correlation between PCWP determined by echocardiographic equation and at cardiac catheterization

\begin{tabular}{lccr}
\hline PCWP (mmHg) & Mean \pm SD & $\begin{array}{c}\text { Pearson } \\
\text { Correlation } \\
\text { co-efficients } \\
\text { (r value) }\end{array}$ & p value \\
\hline $\begin{array}{l}\text { Invasive (mean) } \\
\begin{array}{l}\text { Noninvasive } \\
\text { Equation- }\end{array}\end{array}$ & $20.6 \pm 3.7$ & & - \\
\hline
\end{tabular}

Equation - PCWP: 1.43XDR+1.32XE/A-0.024XDT+0.02XMLAV+9.2 $P$ value reached from Pearson correlation test

$\mathrm{S}=$ Significant $\mathrm{p}<0.05$ )

Significant correlation is illustrated in scatter plot (Fig 7).

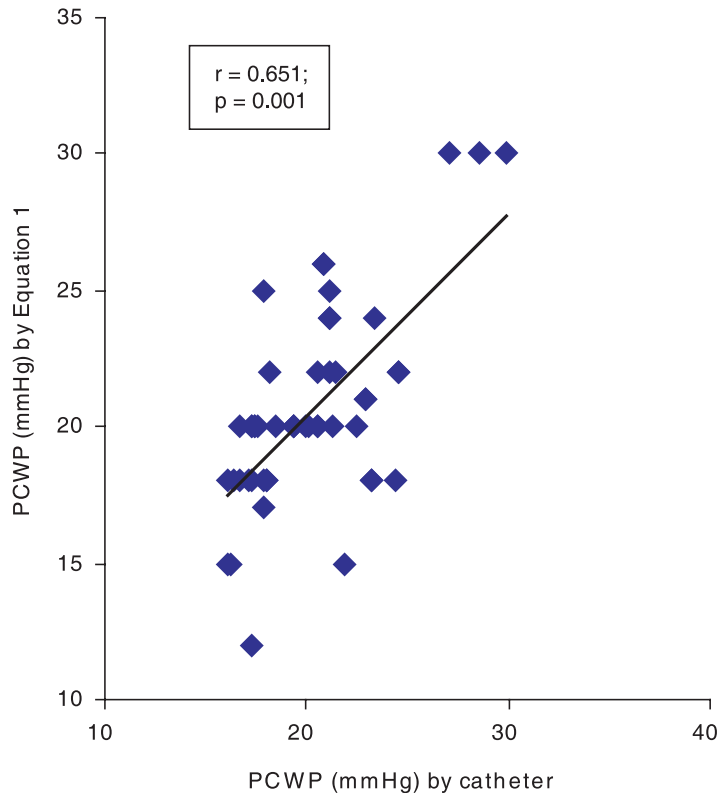

Fig.-7: Scatter plot showing correlation between PCWP $(\mathrm{mmHg})$ measured and estimated
Table 5 demonstrated that no statistically significant mean difference was found between invasive PCWP and PCWP measured by equation derived from transmitral flow velocity parameters

Table-V

Comparison between PCWP obtained by echocardiographic equation and at cardiac catheterizations

\begin{tabular}{lccc}
\hline Parameters (PCWP) & Mean \pm SD & $\mathrm{N}$ & p value \\
\hline Invasive (mean) & $20.6 \pm 3.7$ & 50 & $0.381^{\mathrm{NS}}$ \\
NoninvasiveEquation & $20.2 \pm 2.2$ & 50 & \\
\hline
\end{tabular}

$\mathrm{P}$ value reached from unpaired students t test $\mathrm{S}=$ Significant $(\mathrm{p}<0.05)$

$\mathrm{NS}=$ Not significant $(\mathrm{p}>0.05)$

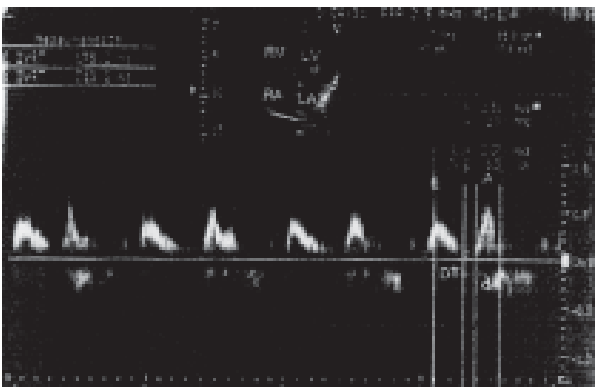

Fig- 8: Indexes of diastolic filling (mitral inflow) Case 1: PCWP-Invasive $15 \mathrm{~mm} \mathrm{Hg}$ Non-invasive $-14.2 \mathrm{~mm} \mathrm{Hg}$

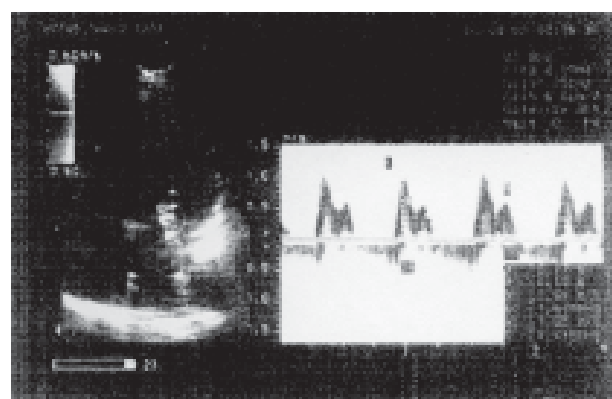

Fig- 9: Indexes of diastolic filling (mitral inflow) Case 2: PCWP - Invasive $25 \mathrm{~mm} \mathrm{Hg}$ Non-invasive - $26.32 \mathrm{~mm} \mathrm{Hg}$ 


\section{Discussion:}

Pulmonary Capillary Wedge Pressure (PCWP) can be reliably estimated in patients with different cardiac diseases by combining Doppler echocardiographic variables in multiple regression analysis. Several studies established the positive correlation of peak early mitral flow velocity (Ewave) and mean PCWP $(r=0.50)$ and also deceleration time of early diastolic mitral flow and mitral flow velocity at atrial contraction (A-wave) were inversely correlated with mean PCWP, with correlation coefficient of $\mathrm{r}=-0.61$ and $\mathrm{r}=-0.57$ respectively. ${ }^{22}$ Our findings are very much consistent with these findings, except our study didn't find any correlation with mitral flow velocity at atrial contraction and PCWP. The possible explanation might be inclusion of heterogeneous groups of patients with restrictive cardiomyopathy. We also found significant positive correlation of $\mathrm{PCWP}$ with deceleration rate $(\mathrm{r}=0.651)$, but didn't find any correlation of PCWP with two other parameters $[(\mathrm{r}=0.066)$ and $\mathrm{r}=0.224)]$ for $\mathrm{E} / \mathrm{A}$ ratio and peak A-wave respectively. A study showed significant positive correlation between PCWP and $\mathrm{E} / \mathrm{A}$ ratio $(\mathrm{r}=0.83)$ and early diastolic deceleration rate $(r=0.80) .{ }^{23}$ In addition, that study also established an inverse relation between mean PCWP and mitral flow velocity at atrial contraction, A-wave $(\mathrm{r}=0.66)$. Our study didn't find any relationship between E/A ratio and left ventricular end diastolic pressure measured invasively in patients undergoing investigation for $\mathrm{CAD}$, which is consistent with another study. ${ }^{24}$ Another study showed highest correlation of PCWP with $\mathrm{E} / \mathrm{A}$ ratio $(\mathrm{r}=0.75)$, significant correlation with $\operatorname{IVRT}\left(\mathrm{r}-=-0.55\right.$ and A-wave velocity $(\mathrm{r}=-0.70) .{ }^{24} \mathrm{Like}$ our study, they found a significant correlation of PCWP with deceleration time of early diastolic mitral flow $(r=-0.50)$ and $E$-wave $(r=0.45)$ and no significant correlation with A-wave duration $(\mathrm{r}=0.12$ $\mathrm{p}=0.49$ ). The best correlation was observed with combination of $\mathrm{E} / \mathrm{A}$ ratio and IVRT in a stepwise multilinear regression equation $(\mathrm{r}=0.79)$. In our study, mitral A-wave duration (dA) showed no difference among haemodynamic subgroups $(\mathrm{r}=$ 0.184 ) which is consistent with another study. ${ }^{25}$ Our study established strongest correlation of PCWP with deceleration rate $(\mathrm{r}=0.651 ; \mathrm{p}=0.001)$ followed by deceleration time $(r=-0.483 ; p=0.001$, peak $\mathrm{E}$ wave $(\mathrm{r}=0.345 ; \mathrm{p}=0.01)$ and ejection fraction $(\mathrm{r}=-0.334 ; \mathrm{p}=0.01)$ and similar findings were observed in previous studies. ${ }^{20}$ In their study the most important determinant of PCWP was the deceleration rate, whereas peak early to late diastolic velocity ratio, deceleration time and maximal left atrial volume provided a smaller contribution, which was consistent with our study. The correlation coefficient between measured and estimated PCWP from equation derived from mitral flow variables by multiple regression analysis was $(\mathrm{r}=0.84)$.

Our study evaluated the same equation for predicting PCWP in a stepwise multiple linear regression analysis and employed Pearson correlation co-efficient to establish the relationship between catheter-derived PCWP and estimated PCWP and also to identify best predictor of measured PCWP. The study found the contribution of different variables in similar order with different $r$-value in equation with correlation coefficient of $(\mathrm{r}=0.678)$. Deceleration rate was the most relevant determinant of PCWP It was found that PCWP determined by the equation had significant positive correlation with PCWP measured by catheter $(p=0.001)$ which was consistent with the result of previous study, but according to that study this equation was the least accurate and highest correlation was obtained by another equation incorporating pulmonary venous flow variables $(\mathrm{r}=0.89) .^{20}$

\section{Limitations of the study}

This study did not include patients with other disease like cardiomyopathy. Accordingly the result cannot be generalized to other patients with more compromised left ventricular function. The study did not measure isovolumic relaxation time which is probably the most sensitive of Doppler indexes in detecting impaired relaxation and significant predictor of PCWP in some studies.

In this study PCWP was measured with Cournand catheter, though it would have been better if we could use Swan Ganz catheter. However, this method is sufficiently reliable for measuring PCWP.

Due to small sample size used in this study, there were non-significant results in most instances and lower values of correlation co-efficients. 


\section{Conclusion:}

Pulmonary Capillary Wedge Pressure (PCWP) is an established index of cardiac function. Regrettably, the determination of PCWP requires an invasive procedure; therefore a noninvasive method for estimating pulmonary artery wedge pressure would be welcomed. The present study provides evidence that in patients with coronary artery disease pulmonary capillary wedge pressure can reliably be estimated by combining Doppler echocardiographic variables of mitral flow. Among the mitral flow variables, deceleration rate is the most important determinant of PCWP. This simple, repeatable, readily available, non-invasive tool may reduce the need for right heart catheterization and may provide us with a bedside method of estimating and monitoring PCWP. Thereby it will make acute haemodynamic monitoring of unstable patients in CCU and ICU and haemodynamic follow-up of patients with congestive heart failure more comfortable and less expensive.

\section{References}

1. Giannuzzi P, Imparato A, Temporelli P.L et al. Doppler derived mitral deceleration time of early filling as a strong predictor of pulmonary capillary wedge pressure in postinfarction patients with left ventricular systolic dysfunction. J Am Coll Cardiol 1994;23: 1630-1637.

2. Vanoverschelde J.L, Robert A.R, Gerbaux A et al. Noninvasive estimation of pulmonary arterial wedge pressure with Doppler transmitral flow velocity pattern in patients with known heart disease. Am $J$ Cardiol 1995; 75:383-389.

3. Nagueh S.F, Kopelen H.A, Zoghbi W.A. Feasibility and accuracy of Doppler echocardiographic estimation of pulmonary artery occlusive pressure in the intensive care unit. Am J Cardiol 1995; 75:1256-1262.

4. Appleton C.P, Galloway J.M, Gonzalez M.S et al. Estimation of left ventricular filling pressures using two dimensional and Doppler echocardiography in adult patients with cardiac disease. J Am Coll Cardiol 1993;22: 1972-1982.

5. Garcia M.J, Ares M.A, Asher C et al. An index of early left ventricular filling that combined with pulsed Doppler peak E velocity may estimate capillary wedge pressure. J Am Coll Cardiol 1997; 29:448- 454.

6. Garcia M.J, Thomas J.D, Klein A.L. New Doppler echocardiographic applications for the study of diastolic function. J Am Coll Cardiol 1998; 32:865-875.

7. Brun P, Tribouilloy C, Duval A.M et al. Left ventricular flow propagation during early filling is related to wall relaxation: a color M-mode Doppler analysis. J Am Coll Cardiol 1992; 20:420-32.
8. Stugaard M, Smiseth O.A, Risoe C et al. Intraventricular early diastolic filling during acute myocardial ischemia: assessment by multigated color M-mode Doppler. Circulation 1993; 88:2705-13.

9. Takatsuji H, Mikami T, Urasawa K et al. A new approach for evaluation of left ventricular diastolic function: Spatial and temporal analysis of left ventricular filling flow propagation by color M-mode Doppler echocardiography. J Am Coll Cardiol 1996; 27:365371.

10. Nishimura R.A, Tajik A.J. Evaluation of diastolic filling of left ventricle in health and disease: Doppler echocardiography is the clinician's Rosetta stone. $\mathrm{J} \mathrm{Am}$ Coll Cardiol 1997; 30:8 -18.

11. Kitabatake A, Inoue M, Asao M et al. Transmitral blood flow reflecting diastolic behaviour of the left ventricle in health and disease - a study by pulsed Doppler technique. Jpn Circ J 1982;46:92- 102.

12. Appleton C.P, Hatle L.K, Popp R.L. Relation of transmitral flow velocity patterns to left ventricular diastolic function: new insights from a combined hemodynamic and Doppler echocardiographic study. $J$ Am Coll Cardiol 1988; 12:426-40.

13. Thomas J.D, Weyman A.E. Echocardiographic doppler evaluation of left ventricular diastolic function. Physics and physiology. Circulation 1991; 84:977-90.

14. Brun P, Tribouilloy C, Duval A.M et al. Left ventricular flow propagation during early filling is related to wall relaxation: a color M-mode Doppler analysis. J Am Coll Cardiol 1992; 20:420 -32.

15. Stugaard M, Brodahl U, Torp H et al. Abnormalities of left ventricular filling in patients with coronary artery disease. Assessment by multigated color M-mode Doppler echocardiography. Circulation 1993; 88:270513.

16. Stugaard M, Brodahl U, Torp $\mathrm{H}$ et al. Abnormalities of left ventricular filling in patients with coronary artery disease. Assessment by colour M-mode Doppler technique. Eur Heart J 1994;15:318 -27.

17. Stugaard M, Risoe C, Ihlen H et al. Intracavitary filling pattern in the failing left ventricle assessed by color Mmode Doppler echocardiography. J Am Coll Cardiol 1994;24:663-70.

18. Takatsuji H, Mikami T, Urasawa K et al. A new approach for evaluation of left ventricular diastolic function: spatial and temporal analysis of left ventricular filling flow propagation by color M-mode Doppler echocardiography. J Am Coll Cardiol 1996; 27:365-71.

19. Duval-Moulin A.M, Dupouy P, Brun P et al. Alteration of left ventricular diastolic function during coronary angioplasty-induced ischemia: a color M-mode Doppler study. J Am Coll Cardiol 1997; 29:1246 -55.

20. Pozzoli M, Capomolia, S, Pinn G et al. Doppler Ecocardiography reliably predicts pulmonary artery wedge pressure in patients with chronic heart failure 
with or without mitral regurgitation. J Am Coll Cardiol. 1996; 27(4): $883-93$.

21. Grossman,W. Pressure measurement' in Cardiac catheterization, angiography and intervention, In: Grossman. W. ed. Lippincott, Philadelphia, 2000; pp. 152-153.

22. Appleton C.P, Hatle L.K, Ropp R.L. Relation of transmitral flow velocity patterns to left ventricular diastolic function: New insights from a combined haemodynamic and Doppler Echocardiographic study. J Am Coll Cardiol. 1998; 12: 426-40.

23. Pozzoli M, Capomolia S, Opasich C et al. Left ventricular filling pattern and PCWP are closely related in patients with recent anterior myocardial infarction and left ventricular dysfunction. Eur Heart J. 19992;13:106773

24. Ettles D.F, Davies J, Williams G.J. Can left ventricular end diastolic pressure be estimated non-invasively? International $J$ Cardiology.1988;20:237-45.

25. Appleton C.P, Galloway J.M, Gonzalez M.S et al.. Estimation of left ventricular filling pressures using two dimensional and Doppler echocardiography in adult patients with cardiac disease. Additional value of analyzing left atrial size, left atrial ejection fraction and the difference in duration of pulmonary venous and mitral flow velocity at atrial contraction. $\mathrm{J} \mathrm{Am} \mathrm{Coll}$ Cardiol. 1993; 22:1972-82. 